MATEC Web of Conferences 52, 01004 (2016)

DOI: $10.1051 /$ matecconf/20165201004

(C) Owned by the authors, published by EDP Sciences, 2016

\title{
Requirements Engineering Model: Role Based Goal Oriented Model
}

\author{
Sandfreni, S.SI, $\mathrm{MT}^{1 \text {, a }}$, Ir. Kridanto Surendro, M.Sc, PhD ${ }^{2}$ \\ ${ }^{1}$ University of Esa Unggul, Faculty of Computer Science, Jakarta, Indonesia \\ ${ }^{2}$ Bandung Institute of Technology, School of Electrical Engineering and Informatics, Bandung, Indonesia
}

\begin{abstract}
Requirements engineering approach through intentional perspective is one of the arguments that appear in the field of requirement engineering. That approach can explain the characteristics of the behavior of an actor. The usage Goal Based Workflow and KAOS method in iStar modeling might help the system analyst to gain knowledge about the internal process inside each of actor sequentially, such that the whole sequential activity to achieve the goal are exposed clearly in those actor's internal process. The adoption of the concept of the role of RACI diagram on Role Based Goal Oriented Model system analyst gain complete knowledge about requirements of actor who involve in a system. System analyst might also distinguish the dependency between each actor in each process. Those dependencies are exhibited in strategic dependency model. In addition, the internal activities of the actor are also shown in strategic rationale model.
\end{abstract}

\section{Introduction}

Requirement Engineering is the first step in the adoption of an information system. Requirements Engineering has a purpose to understand the system users needs, which is realized by identifying the involved component in the system. Requirement Engineering in Software Engineering that identifies the actual user's requirement is a critical part that determines the successfulness of system development. The main constraint in gathering the requirement is the difficulties in understanding the application domain [1].

Designing a system that suitable with the user requirement is still challenging. This challenge is lied on the difficulty to rely on the results of mainly found in the difficulty to rely on the results of catching system requirement [2]. When users express their needs, all of those requirements is only the beginning concept of the solution, hence the actual needs is still unrevealed [2]. Because Requirement Engineering is a bridge that connects the world of informal stakeholder needs with the world of formal system behavior, therefore the understanding of the system, the conceptualization of system character, identification of the system constraints, understanding of system development cycle, and system analyzation are required [3].

Requirements engineering approach through intentional perspective is an arguments that appear in the field of requirement engineering. That approach is able to explain the characteristics of an actor behavior, with the expected model by an actor that can be obtained without specifying their behavior

${ }^{a}$ Corresponding author : sandfreni@esaunggul.ac.id 
precisely. In the $i^{*}($ iStar) modeling that focused on intentional perspective and understand the relationship between actors in a domain of behavior, but rather to how the system can help improve the relations between social actors in an organization [4].

Several researches on iStar modeling have produced various requirements engineering model. iStar modeling has represented successfully the relation between actors in term of tasks, goals and resources. iStar can also describe the processes that occur on each actor. iStar has been modified to represent the requirements model in hierarchical based on organizational structure, in such way relationship between actor are possible to be observed on organization level that has been written in Requirement Engineering Model for Cloud Computing University Using iStar Hierarchy Method [5]. But until now the development of modeling iStar can't representing about role in a process explicitly.

\section{Literature Review}

\subsection{The Approach of Goal to Understand The Organization's Situation and Needs}

In understanding the organization needs, the way to represent knowledge of the domain, structurally is needed. Describe the overall business situation and also includes cooperation between actors and goals of each group in the organization. In describing the situation, goal has a function as a motivation resource from each intentionality, which is manifested in actions, or procedures that occur in the organization.

\subsection{Goal Based Workflow}

Goal based workflow approach describes the interaction between actor that associated with goal. In this approach goal is represented explicitly. The model express the organization of tuple [G, A, R], where G is the "goal" set, A is the "actor" set, and R is the "resource" set [6]. A set of actor will collaborate utilizing a set a resource to achieve the organization's goal from an organization, such as depicted in the figure 2.

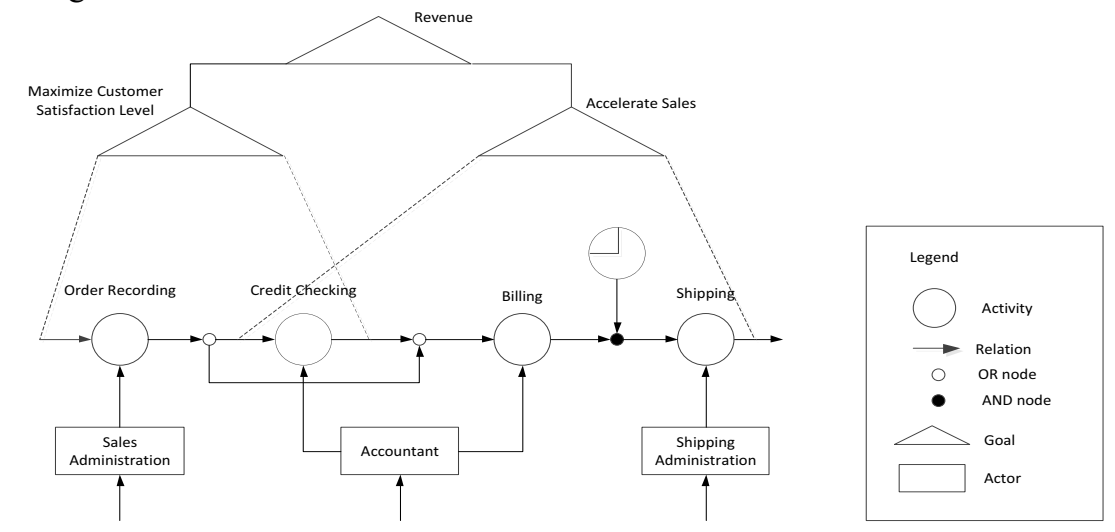

Source: Goal Based Workflow (Kavakli, 2003)

Figure 1 Goal Based Workflow

\subsection{Keep All Objects Satisfied (KAOS)}

KAOS might be described as the framework from several paradigms that enables to combine various different level of thought along with its reasoning. KAOS modeling language is part of KAOS framework to elicit, specify, and analyze goals, requirement, scenario and tasks responsibility [4].

The Element of KAOS [4] consists of following terms: 
- Goal is defined as the set of behavior or circumstance that have to be fulfilled or accepted by the system in the predefined condition [7]. The goal definition must be clear enough such that could be verified if the system is able to fulfill that goal.

- Softgoal is used to documentions the system's alternative behavior, such that its satisfaction could be verified. The satisfaction level of the softgoal is restricted by the predefined limit.

- An agent is the object that has a function to process the activity operation. An agent, that is an active component, could represent human, hardware, software, that has specific role in achieving the goal.

- There are three kinds dependencies between goals in KAOS [4]:

- AND/OR-decomposition is the relation that describes the hierarchy of goal and its sub-goal. It explains a goal is achieved if all of its sub-goal is achieved (using AND decomposition) or if there is at least one of its sub goals is achieved (using OR decomposition).

- Potential conflict is the relation that express in certain condition the achievement of a goal would hinder the achievement of another goal. This conflict usually appears if there are any differences among stakeholder's interest and point of view [7].

- Responsibility assignment is the relation between agent and a goal. The agent has the responsibility to achieve the goal.

\section{4 iStar}

The iStar(i*) approach is centered on the stakeholder of the system and also the relationship between stakeholder. Through this approach the requirements of the systems could be learn easily, especially if there is specific requirement in the domain, and also preparing the change of requirement in the future [2].

iStar approach express the dependability between actor and the goal that should be achieved, task that should be done, and resource that should be provided. In addition of goal, softgoal is also introduced to express non-functional requirement. The $\mathrm{i}^{*}$ name itself stand for "distributed intentionality, in which $i^{*}$ place the intention of the actor in the context of social network between actors [4]. Those actor could be referred to human or machine. Actors are described as entity that can act freely, restricted by its relation with another actor, cannot be known or controlled fully, and have explicit knowledge to exercise certain action [4]. In order to describe the actor entity, $i^{*}$ complements it with motivation and intention attribute [4]. Instead of focus on actor behavior, intention and relation property is used to describe the actor. Actor has a relation with another actor, due to there is goal that want to be achieved, task that should be done, and resource that should be provided.

Dependency that describe the intentional relationship between two actor are represented in following term:

\section{Actor1 $\rightarrow$ Dependum $\rightarrow$ Actor2}

Where "dependum" means kind of dependency and explain the deal between two entities. The first actor is the party that needs something from the second actor. Type of dependency can be categorize into 4 types [4]:

- Goal is the condition or circumstance to be achieved by the stakeholder. It is stated as emphasizing in representation language. How to goal could be achieved is not defined, therefore the alternative should be considered.

- Task defines the certain course to do some action. If task is defined as the subcomponent of higher task, it restricts the higher task to certain action.

- Resource is an entity (physically or information). The main concern here is the availability of the resource and identifies the provider if external party provides it.

- Softgoal is the condition that has subjective level of satisfaction. Its purpose is not defining precisely only follow its interpretation. 
iStar Modeling consists of:

1) Strategic Dependency (SD), describes the dependency relationship between actor, that is the strategy of each actor to understand:

a. What do they need?

b. How they can achieve their needs?

c. To whom they depend in achieving their need?

2) Strategic Rationale (SR), modelize what is happening inside actors, and how the actors achieve their need. SR models consists of:

a. Mean - end link: represents the task that need to be done to achieve the final result. The final result could be goal, task, resource or softgoal.

b.Task decomposition link: represents the relation between task and its subcomponent. Its subcomponent could be goal, task, resource and softgoal.

Contribution link: represents how positive is the goal's, resource's, or task's contribution to the achievement of certain softgoal.

\subsection{RACl (Responsible, Accountable, Consulted, Informed)}

RACI Chart is the matrix that describes the role of parties in completing certain work on a project of a business process. This matrix is very useful in explaining the role and responsibility of entity in a project or process. RACI itself is stood for Responsible, Accountable, Consulted and/or Informed. As can be seen in figure 2 RACI chart [8]:

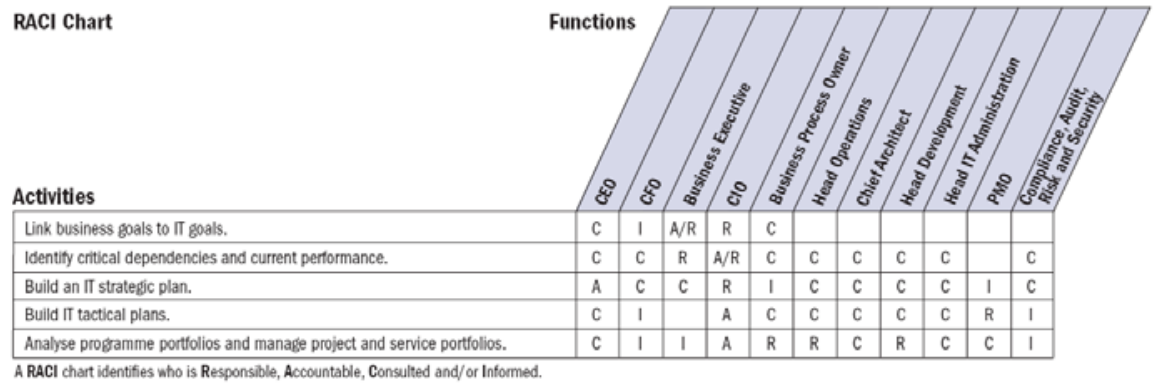

Source: IT Governance, 2007

Figure 2 RACI chart

Following are the description of RACI chart value:

- Responsible: The person or entity who exercise the activity.

- Accountable: The person or entity that responsible has the authority to take the decision in certain circumstance.

- Consulted: The person or entity that his feedback and advice is required to complete the activity.

- Informed: The person or entity that has the right to know the result of the activity or the decision.

\section{Research Methodology}

The perspectives and experiences of the researcher influence a research design. These views and experiences are used to guide how and for whom the research problem is being investigated, what research approach and methods of gathering suitable research data will be used.

Author will focus on developing new modeling framework based on the existing goal and intentional based modeling framework. The comparison between existing modeling framework, and how each model influences the proposed modeling framework will be described. Finally, the author will make a modeling framework and describe the sequence process needed to implement the framework to the real case. 


\section{Role Based Goal Orientation}

In this study, this model analyzed based on four criteria: description of goal, actor, softgoal, and task and event. Analysis of requirement engineering models in describing the goal, actor, softgoal, task and event notation and briefly summarized in Table 1 is a table of analysis among models.

From the summary Table 1, models will be chosen is the model that will become a basic reference in the design requirement engineering approach and must have the ability to represent a goal and derivatives of these goals in detail relations and cooperation between the actors in the domain that will be described. Model iStar is the right model to serve as a basic reference in this study. But iStar models also have shortcomings, i.e cannot represent the role of the actor, therefore needed a concept that can represent the role of the actor. Based on the results of literature study RACI diagram is an appropriate concept to be adopted in this modeling.

RACI in an organization is necessary, because it describes positions, roles and functions of each actor in the organization. RACI defines the responsibility of each actor in the organization for each business process. RACI allows the business process designer to allocate actor's responsibility on every business process vary from each other according to the needs of the business process, which makes RACI is flexible. RACI can also identify if there is overload of work on an actor, so the distribution of responsibility can be optimized.

Therefore it can be concluded that the concept of RACI is highly appropriate to fulfill deficiencies in this model because RACI is useful to identify actors and relationships between actors in the modeling that describes the dependence of the actors of the goal to be achieved, the task will be done and the resources that will be provided.

Table 1 Table of comparison among models

\begin{tabular}{|l|l|l|l|l|}
\hline Model & Goal & Actor & Softgoal & Task and Event \\
\hline $\begin{array}{l}\text { KAOS, } \\
\mathbf{1 9 9 0}\end{array}$ & $\begin{array}{l}\text { Has 4 models } \\
\text { representation.In } \\
\text { modeling goal, } \\
\text { task is not } \\
\text { expressed. }\end{array}$ & $\begin{array}{l}\text { Only knows agent concept. } \\
\text { Cooperation between } \\
\text { agents can not be observed } \\
\text { explicitly. There is not } \\
\text { actor role in the process. }\end{array}$ & $\begin{array}{l}\text { Softgoal is represented as } \\
\text { goal. The constraint in } \\
\text { achieving the goal is } \\
\text { expressed as obstacle. }\end{array}$ & $\begin{array}{l}\text { Task has more detail } \\
\text { representation in } \\
\text { operational model, by } \\
\text { expressing the } \\
\text { relationship between } \\
\text { event and task. }\end{array}$ \\
\hline $\begin{array}{l}\text { Goal } \\
\text { Based } \\
\boldsymbol{W o r k f l o} \mathbf{1 9 9 4}\end{array}$ & $\begin{array}{l}\text { Has goal } \\
\text { representation, } \\
\text { which is derived } \\
\text { into simpler goal. }\end{array}$ & $\begin{array}{l}\text { Introduces actor concept, } \\
\text { but the relationship } \\
\text { between actor can not be } \\
\text { observed. There is not actor } \\
\text { role in each of process. }\end{array}$ & $\begin{array}{l}\text { Does not introduce softgoal } \\
\text { concept. }\end{array}$ & $\begin{array}{l}\text { Task and event concept } \\
\text { are represented by } \\
\text { activity. The model } \\
\text { expresses the sequence } \\
\text { of activity in achieving } \\
\text { the goal. }\end{array}$ \\
\hline $\begin{array}{l}\text { iStar, } \\
\mathbf{1 9 9 5}\end{array}$ & $\begin{array}{l}\text { Has goal and } \\
\text { softgoal } \\
\text { representation, } \\
\text { and also expresses } \\
\text { task and another } \\
\text { entities in the } \\
\text { same model. }\end{array}$ & $\begin{array}{l}\text { Shows the cooperation } \\
\text { between actors explicitly. } \\
\text { There is not further } \\
\text { exploration on role and } \\
\text { position of actor (even } \\
\text { though there is available } \\
\text { syntax) }\end{array}$ & $\begin{array}{l}\text { Has softgoal representation, } \\
\text { and negative or positive } \\
\text { contribution relationship, by } \\
\text { which the progress of softgoal } \\
\text { achievement can be observed. }\end{array}$ & $\begin{array}{l}\text { Model iStar can not } \\
\text { express the operational } \\
\text { side of view, which is } \\
\text { the sequence of event in } \\
\text { achieving the task. }\end{array}$ \\
\hline
\end{tabular}

\subsection{Deconstruction Model}

Translation of the model modification from models deconstruction can be seen in Table 2, Table Deconstruction Model

Table 2 Table Models Deconstruction

\begin{tabular}{|l|l|l|}
\hline Model/Concept & Proses & Output \\
\hline Goal Based Workflow & Deconstruction & $\bullet$ Sequence \\
\hline KAOS & Deconstruction & $\bullet$ Task \\
\hline
\end{tabular}




\begin{tabular}{|l|l|l|}
\hline Model/Concept & Proses & \multicolumn{1}{|c|}{ Output } \\
\hline iStar & Pra Deconstruction & $\bullet$ Strategic Rationale Notation \\
& & $\bullet$ Strategic Dependency Notation \\
\hline iStar: Strategic Rationale & Deconstruction & $\bullet$ Goal \\
& & $\bullet$ Resource \\
\hline iStar: Strategic Dependency & Deconstruction & $\bullet$ Actor \\
\hline RACI & Adoption & $\bullet$ Role \\
\hline
\end{tabular}

From the results of Table 2 the obtained models proposed are composed by elements of the output of the process from deconstruction on every model.

To further improve the modeling is made, then the first deconstructed into elements essential constituent of the proposed model.

The proposed model consists of two notations models:

1. Strategic Dependency; In building the strategic dependency notation on the proposed model used the following considerations:

a. The basic model used is a model of strategic dependency on istar.

b.iStar strategic models doesn't show the dependency on the role of each actor on each process, requiring modifications to the notation to describe the role of the actor on every process.

c. In the proposed model uses the concept of RACI diagram to explain the role of each actor, and then roles in the RACI diagram notation on the model adopted as proposed strategic dependency.

2. Strategic Rationale; In building the strategic rationale notation on the proposed model used the following considerations:

a. The basic model used to create the strategic rationale notation is modeled on istar strategic rationale model.

b. Strategic Rationale model on istar illustrates the task that will do by each actor in order to achieve the goal of every actor, but does not show the sequential order of the task performed by the actor.

c. To illustrate the sequential task sequence then adopted elements of Goal-Based Workflow modeling. KAOS has event concept that is used as a substitute for the task on Strategic Rationale for on proposed model.

\subsection{Design Process Model}

The proposed model called Role-Based Goal Oriented Model is derived from the characteristics of the model created. Role-Based Goal Oriented Model has two main notations the same as the model iStar(i*), namely strategic dependency and strategic rationale that has been modified.

Strategic dependency consists of six stages, as depicted in figure 3. At the end of this stage, strategic dependency notation is obtained as the final result (see on Appendix A).

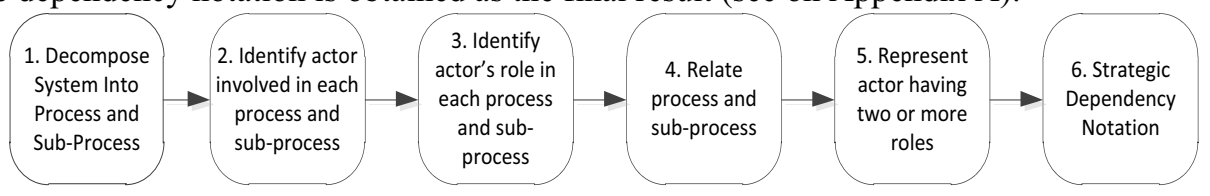

Figure 3. Stages Modelling Notation proposed Strategic Dependency

Furthermore, the strategic rationale modelling stage consists of four stages, as depicted in figure 4 . At the end of this stage, strategic rationale notation is obtained as the final result (see on Appendix A). 


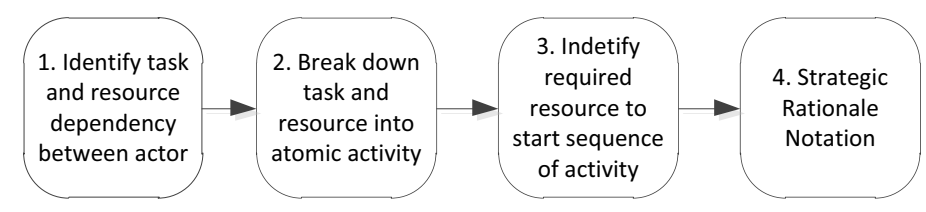

Figure 4. Stages Modeling Notation proposed Strategic Rationale

Having obtained a complete figure of the internal activities inside the actor, the next step is to draw notation strategic rationale. One strategic rationale notation represents one entry in the column actors. Sequences of activity become a task on the strategic rationale.

\section{Conclusion and Further Research}

\subsection{Conclusion}

Based on the discussion of the research that has been done, produced some of the conclusions that can be delivered as follows:

1. Modeling iStar at the time of requirement engineering can be more easily understood, especially aware of any special requirements in a domain and also can determine the understanding of the relationship between actors. But in the absence of modeling iStar furthers exploration of the role and position of actors in each process and cannot display the operational side, the series of events that occur in living a task.

2. By modifying modeling Role modeling Based iStar be Goal Oriented proven model can also determine the dependence between actors and also the role and position of actors in each process shown by strategic dependency and can identify what activities are happening at each actor sequentially so it is clearly visible construction sequences to achieve the goal in the internal processes of the actors represented by the strategic rationale.

\subsection{Further Research}

Suggestions for further research are as follows:

1. In Role Model Based Goal Oriented Construction needed a tool that is appropriate to adopt this model.

2. The development of this model can also be used in different organizational forms that involve actors who are part of the organization.

\section{References}

[1] Curtis, B., Krasner, H., \& Iscoe, N. (1988). A Field Study of the Software Design Process for Large Systems. Communications of the ACM, 31(11), pp.1268-1287

[2] Yu, Eric, Paolo Giorgini, Neil Maiden, and John Mylopoulos. (2011) : Social Modelling for Requirement Engineering: An Introduction. Social Modelling for Requirements Engineering. MIT Press.

[3] Nuseibeh, Bashar, and Steve Easterbrook. (2000): Requirements Engineering: A Roadmap. ICSE 2000 Proceedings of the Conference on The Future of Software Engineering

[4] Yu, Eric: Social Modeling and i*. Conceptual Modeling: Foundations and Applications. Springer, 2009.

[5] Sandfreni, Oktadimi, N. R., Surendro, K. (2015): Requirement Engineering for Cloud Computing in University using i*(iStar) Hierarchy Method. Information Science and Application. Lecture Note in Electrical Engineering, pp 885-890. 
[6] Kavakli, E., dan Loucopoulos, P. (2004). Goal Modelling in Requirements Engineering: Analysis and Critique. Of Currents Methods, Informastion Modelling Methods and Methodologies. 104-124

[7] Hui, B., Liaskos, S.m Mylopoulos, J., "Requirements Analysis for Customizable Software: A Goals-Skills-Preferences Framework". Proc. International Conference on Requirements Engineering (RE'03), Monterey, USA, September 2003.

[8] Janssen, M. \& Cresswell, A. (2005) An Enterprise Application Integration Methodology for EGovernment. Journal of Enterprise Information Management, 18(5), pp.531-547.

\section{Appendix A}

Strategic Dependency Notation

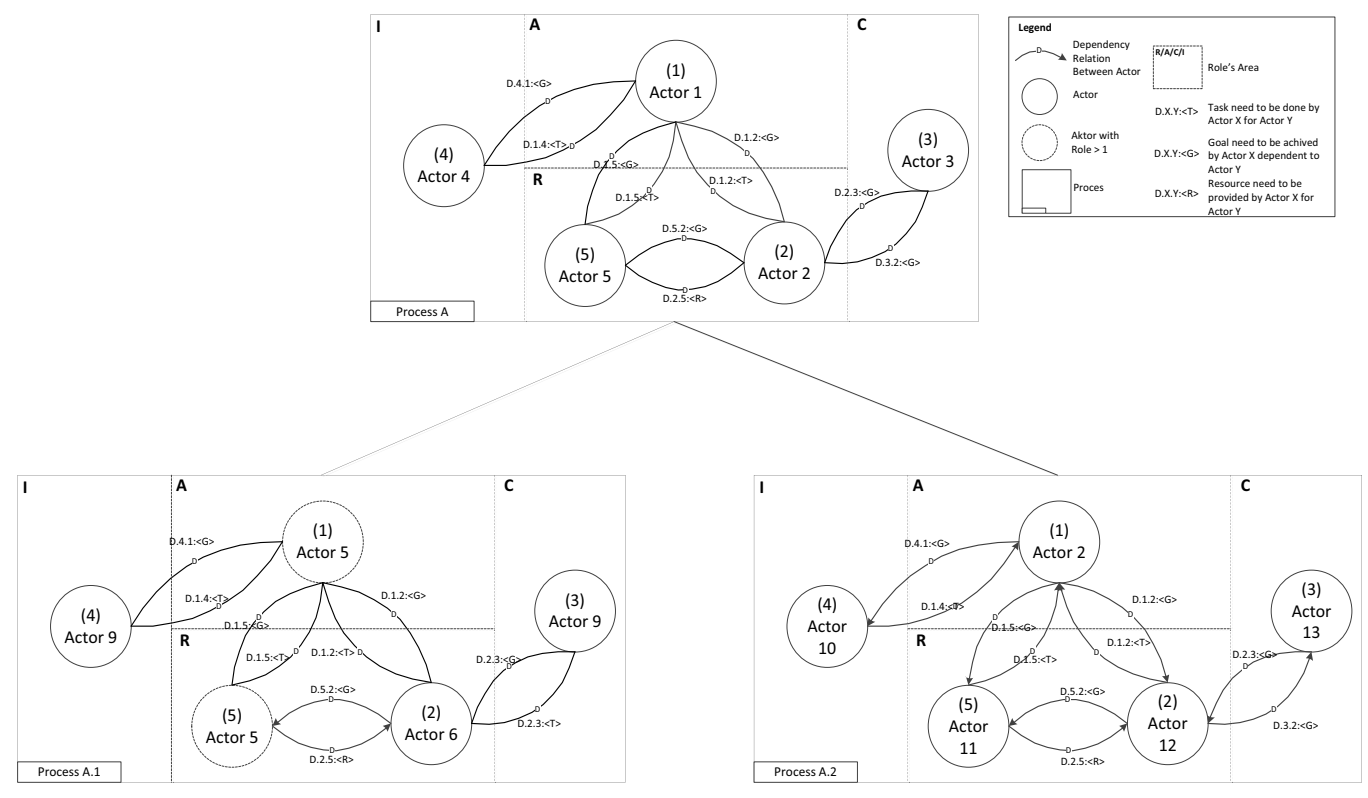

Strategic Rationale Notation

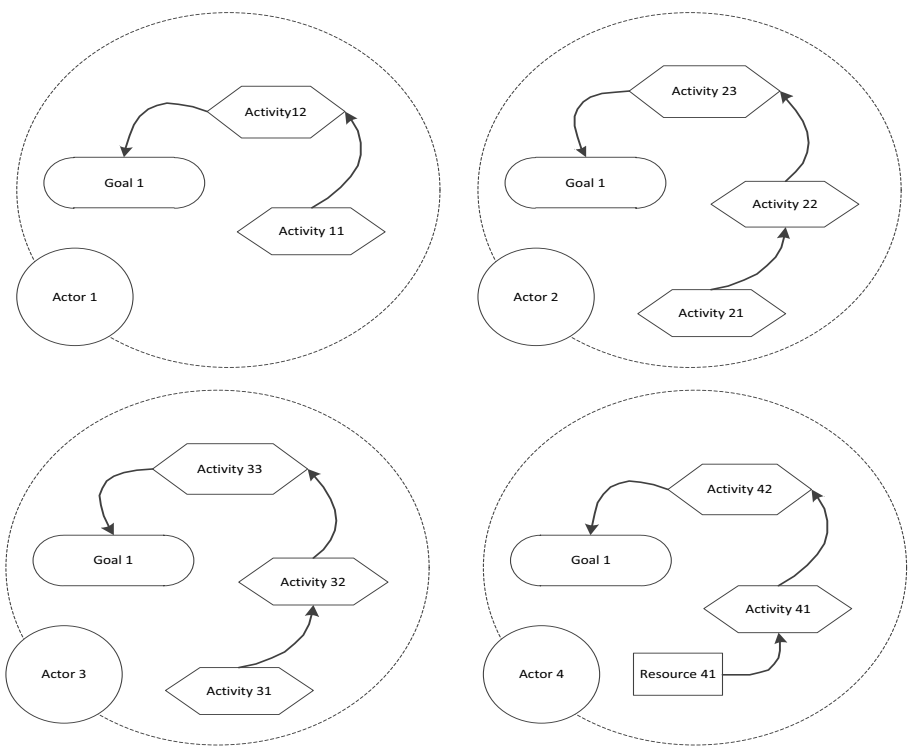

